\title{
Организационно-педагогические условия адаптации военных специалистов к профессиональной деятельности в процессе подготовки по военно-учетным специальностям
}

\author{
Корытков В.А. \\ Новосибирский государственный педагогический университет, \\ Россия, 630126, г. Новосибирск, ул. Вилюйская, 28 \\ E-mail: vladalex-kor@yandex.ru
}

\begin{abstract}
Аннотация. В условиях непрерывного совершенствования средств ведения войны подготовка военных специалистов должна сводиться к их постоянной адаптации к изменяющимся требованиям военно-профессиональной деятельности, в том числе и в ходе их подготовки по конкретной военно-учетной специальности. Совершенствование системы адаптации военных специалистов к профессиональной деятельности традиционными методами уже не может дать нужных результатов. В связи с этим, опираясь на исследования отечественных ученых, автор уточняет определение категории «организационно-педагогические условия». Выделены основные признаки, характерные для организационно-педагогических условий. Выявлены и обоснованы организационно-педагогические условия адаптации военных специалистов к профессиональной деятельности в ходе подготовки по военно-учетным специальностям. Раскрыты основные направления реализации организационно-педагогических условий в Военном учебном центре Сибирского федерального университета. Дан краткий анализ результатов опытноэкспериментальной работы по определению уровня адаптированности студентов Сибирского федерального университета, проходящих обучение по программам военных специальностей.
\end{abstract}

Ключевые слова: военные специалисты, организационно-педагогические условия, адаптация к профессиональной деятельности, адаптированность, адаптационный потенциал, адаптивное образовательное пространство, военно-патриотическое воспитание, профессионально-значимые качества.

Для цитирования: Корытков В.А. 2020. Организационно-педагогические условия адаптации военных специалистов к профессиональной деятельности в процессе подготовки по военно-учетным специальностям. Вопросы журналистики, педагогики, языкознания, 39 (2): 238-245. DOI 10.18413/2712-7451-2020-39-2-238-245

\section{Organizational and pedagogical conditions of adaptation of military specialists to professional activities in the process of training in military accounting specialties}

\author{
Vladimir A. Korytkov \\ Novosibirsk State Pedagogical University, \\ 28 Vilyujskaya St, Novosibirsk, 630126, Russia \\ E-mail: vladalex-kor@yandex.ru
}

\begin{abstract}
In conditions of continuous improvement of means of warfare, the training of military specialists should be reduced to their constant adaptation to the changing requirements of military professional activity, including during their training in a specific military accounting specialty. Improving the system of adaptation of military specialists to professional activities by traditional methods can no
\end{abstract}


longer give the desired results. In this regard, based on the research of domestic scientists, the author clarifies the definition of the category "organizational and pedagogical conditions". The main features characteristic of organizational and pedagogical conditions are highlighted. Organizational and pedagogical conditions of adaptation of military specialists to professional activities during training in military accounting specialties are identified and justified. The main directions of implementation of organizational and pedagogical conditions in the military training center of the Siberian Federal University are revealed. A brief analysis of the results of experimental work to determine the level of adaptation of students of the Siberian Federal University who are trained in military specialties is given.

Keywords: military specialists, organizational and pedagogical conditions, adaptation to professional activities, adaptability, adaptive potential, adaptive educational space, military-patriotic education, professionally significant qualities.

For citation: Korytkov V.A. 2020. Organizational and pedagogical conditions of adaptation of military specialists to professional activities in the process of training in military accounting specialties. Questions of journalism, pedagogy, linguistics, 39 (2): 238-245 (in Russian). DOI 10.18413/2712-74512020-39-2-238-245

\section{Введение}

Современная военно-политическая обстановка характеризуется нарастанием военных угроз. Все больше государств переориентируют свою политику на неограниченные, упреждающие действия наступательного характера. Растет конфликтный потенциал в стратегически важных для России регионах. Возникают новые способы и средства вооруженной борьбы. Эта вооруженная борьба в настоящее время приобретает выраженный наземно-воздушно-космический характер, ее отличительными особенностям являются избирательность поражения объектов и группировок войск и объектов, быстрота маневра подразделениями и огнем, скоротечный характер.

Новые способы ведения вооруженной борьбы в большинстве своем основаны на современных технологиях и технике, высокая эффективность которых доказана в боевых действиях Воздушно-космических сил России на территории Сирии.

В условиях непрерывного совершенствования средств ведения войны можно говорить о том, что подготовка военных специалистов сегодня должна сводиться к их постоянной адаптации к изменяющимся требованиям военно-профессиональной деятельности, в том числе и в ходе их подготовки по конкретной военно-учетной специальности. Вместе с тем совершенствование системы адаптации военных специалистов к профессиональной деятельности традиционными методами уже не может дать нужных результатов. В первую очередь необходимо разработать и реализовать организационно-педагогические условия, которые способствовали бы повышению эффективности и качества адаптации военных специалистов к профессиональной деятельности в процессе их подготовки по военно-учетным специальностям.

\section{Объекты и методы исследования}

Объектом исследования являются организационно-педагогические условия адаптации к будущей профессиональной деятельности военных специалистов в ходе их военнопрофессиональной подготовки.

Методологической основой разработки проблемы адаптации военных специалистов к профессиональной деятельности в процессе их подготовки по военно-учетным специальностям явились труды отечественных исследователей: В.А. Адольфа [2017], Х.А. Асьянова [2000], В.А. Беликова [2010], Г.П. Жилина [2001], М.В. Зверевой [1987], В.В. Игнатовой [2014], В.В. Краевского [1994], С.Н. Павлова [1999], в которых анализируются сущность и содержание категории «организационно-педагогические условия»; 
К.А. Абдульхановой-Славской [1980], М.В. Ромма [2003], выдвинувших в центр своего исследования проблему адаптационного потенциала; В.Г. Афанасьева [1981], Л.С. Выготского [2010], А.Г. Ковалева [1980], К.К. Платонова [1986], С.Л. Рубинштейна [2000], выявляющих психологические особенности личности.

Теоретико-методологический уровень исследования в сочетании с решаемыми задачами прикладного характера предопределил выбор автором теоретических и эмпирических методов исследования: понятийно-терминологический анализ философских, психолого-педагогических трудов; метод анализа нормативно-правовых документов в области деятельности Вооруженных сил России по вопросам профессиональной подготовки военных специалистов; метод прогнозирования и перспективного планирования; метод моделирования; метод констатирующего и результирующего эксперимента.

\section{Результаты и их обсуждение}

Прежде всего необходимо уточнить понятие «организационно-педагогические условия», так как «определение понятия является важнейшим методологическим принципом раскрытия сущности исследуемой проблемы» [Краевский, 1994, с. 34], важнейшим элементом управления инновационными процессами [Жилин, 2001, с. 8].

Опираясь на анализ работ вышеприведенных исследователей, под организационнопедагогическими условиями адаптации военных специалистов к профессиональной деятельности автор рассматривает комплекс целенаправленно спроектированных, находящихся во взаимной связи и взаимной обусловленности мер функционирования субъектов профессиональной адаптации как составной части педагогической системы, которая отражает внешние и внутренние элементы, позволяющие обеспечить успешность ее развития и функционирования. В качестве характеристик организационно-педагогических условий в данном случае можно назвать содержание, организационные формы, методы и средства обучение и воспитания, характер взаимоотношений между обучающими, обучаемыми и учебными материалами [Зверева, 1987; Игнатова, 2014].

В процессе обоснования организационно-педагогических условий адаптации военных специалистов к профессиональной деятельности автор исходил из целей и планируемых результатов данного процесса, методологических подходов, положенных в основу данного исследования, а также учитывались особенности процесса адаптации военных специалистов в Военном учебном центре Сибирского федерального университета. На основе этого автором выявлены и обоснованы следующие организационно-педагогические условия адаптации к будущей профессиональной деятельности военных специалистов в ходе их профессиональной подготовки:

- диагностика адаптивных качеств будущих военных специалистов;

- формирование единого, целостного, преемственного адаптивного образовательного пространства профессиональной подготовки военных специалистов в интересах совершенствования процесса их адаптации к профессиональной деятельности;

- обеспечение личностно-деятельностной основы профессиональной адаптации путем целенаправленного формирования у военных специалистов профессионально значимых качеств в процессе образовательной, военно-служебной и других видов деятельности, воспитательной работы.

Первым шагом процесса адаптации к будущей профессиональной деятельности военного специалиста в процессе его подготовки автор выделяет диагностику его адаптационного потенциала. Необходимость этой диагностики обусловлена потребностью командиров и начальников в получении объективной и всесторонней информации о личностных качествах будущих военных специалистов и их учета в процессе их адаптации к профессиональной деятельности. 
Адаптация военного специалиста к его профессиональной деятельности требует в первую очередь определенного комплекса личностных качеств и способов поведения, которые составляют «адаптационный потенциал» военного специалиста. Адаптационный потенциал представляет собой оценку опыта личности военного специалиста и степени прочности его адаптивных возможностей. Его можно положить в основу мониторинга развития адаптационных способностей личности военного специалиста, как на этапе становления, так и на этапах его профессионального развития.

Ряд исследователей отождествляют адаптационный потенциал с понятием «адаптивности» для использования его при обозначении всех свойств, выражающих способность военного специалиста к приспособлению [Абдульханова-Славская, 1980].

Для исследования адаптационного потенциала будущих военных специалистов на констатирующем этапе опытно-экспериментальной работы, проведенной в 2014-2019 гг., было избрано 400 студентов Сибирского федерального университета.

Основными критериями и показателями уровня адаптационного потенциала были определены следующие:

- когнитивный: представления и знания военного специалиста о себе как активном участнике процесса адаптации, его представления об общей системе способов и приемов адаптации в военно-профессиональной среде;

- мотивационно-ценностный: представляет собой мотивацию на успех в ходе адаптации; установку на активный поиск изменений своего положения в процессе адаптации (поисковая активность);

- деятельностно-практический: навыки саморегуляции психического и эмоционального состояния в состоянии стресса; способность регулировать свое поведение в процессе адаптации (поведенческая регуляция);

- рефлексивный: умение анализировать и контролировать свою деятельность в процессе адаптации, видеть ее цели и результаты; способность адекватно оценивать выбранную стратегию адаптации; готовность к постоянной корректировке своей повседневной деятельности.

Результаты диагностики уровня сформированности адаптационного потенциала будущих военных специалистов показали, что преобладающим уровнем развития адаптационного потенциала является низкий уровень - 48 \% опрошенных. Творческий уровень адаптационного потенциала выявлен у 17,5 \% студентов, а средний у 34,5 \% респондентов.

У студентов с низким уровнем адаптивности нет адекватного представления о себе как участнике адаптационного процесса, у них преобладает мотивация на неудачу. Для них характерна частая потеря самоконтроля в стрессовой ситуации.

Студенты со средним уровнем развития адаптационного потенциала правильно представляют себя как участников адаптационного процесса. Характерным для них является неопределенность мотивации, признание уставных норм и правил поведения, но необязательность их исполнения. В стрессовой ситуации поведение не всегда правильное, не вполне развито умение сохранять самообладание.

Для студентов с высоким уровнем развития адаптационного потенциала характерно глубокое знание о себе как субъекте адаптационного процесса, определенность мотивации на успех, признание уставных норм и правил поведения и следование им, адекватное поведение в стрессовых ситуациях, высокий уровень развития рефлексивности.

Результаты данного исследования были учтены при реализации следующих организационно-педагогических условий адаптации военных специалистов к профессиональной деятельности в Сибирском федеральном университете.

Рассматривая организационно-педагогические условия адаптации к будущей профессиональной деятельности военных специалистов в ходе их военно-профессиональной подготовки, необходимо отметить следующее. Во-первых, в педагогической науке поня- 
тие единого, целостного, преемственного адаптивного образовательного пространства стало все чаще употребляться в связи с обозначением той части социального пространства, в пределах которой обществом осуществляется нормированная образовательная деятельность. Эта часть социального пространства трактуется как динамическое единство субъектов образовательной деятельности и системы их отношений [Михайлова, 2010; Кочнева, 2015; Адольф, Дашкова, 2017].

При формировании адаптивного образовательное пространства преследовалась цель активизировать деятельность обучающегося и развить в нем имеющийся потенциал саморазвития. Использование военным специалистом возможностей воспитательной и образовательной среды позволяет ему активнее пройти адаптацию к профессиональной деятельности [Адольф, Дашкова, 2017; Адольф, Фоминых, 2017].

Во-вторых, исследование процесса адаптации военных специалистов к профессиональной деятельности с позиций личностно-деятельностного подхода потребовало обращения к реальной личности военного специалиста, к формированию его интеллектуальных, волевых, эмоциональных и других личностных качеств, необходимых для осуществления им военно-профессиональных функций.

Обращение к работам отечественных ученых, исследующих психические особенности личности (А.Г. Ковалев [1980], В.Г. Афанасьев [1981], К. К. Платонов [1986], В.А. Адольф [2017], С. Л. Рубинштейн [2000]), позволило автору выделить следующие профессионально-важные качества личности военного специалиста:

- мотивы и ценности;

- организационно-волевые качества (терпение, воля, самоконтроль);

- умственные способности;

- эмоциональная стабильность;

- стрессоустойчивость;

- умение преодолевать трудности военной службы.

Рассматривая процесс реализации данных условий адаптации военных специалистов к профессиональной деятельности на примере Сибирского федерального университета, автор исходил из того положения, что профессиональная подготовка является ведущей и определяющей характер адаптации военного специалиста к профессиональной деятельности. Поэтому профессиональная подготовка рассматривается автором основным средством адаптации, представляется как процесс включения в специальность, овладения навыками и умениями профессиональной деятельности, формирования профессионально важных качеств [Безюлева, 2008].

Исходя из этого, в качестве стратегии реализации организационно-педагогических условий адаптации военных специалистов к профессиональной деятельности в процессе освоения ими военно-учетных специальностей автор выдвинул, во-первых, системную интеграцию всех подсистем подготовки к профессиональной деятельности в единую педагогическую систему в интересах обеспечения эффективного протекания процесса адаптации; во-вторых, обогащение знаний, навыков и умений на основе активных педагогических технологий.

В процессе исследования в Сибирском федеральном университете системная интеграция реализовалась как интеграция содержания образовательного процесса по программам высшего образования и по программам военно-профессиональной подготовки студентов. Учебные дисциплины, осваиваемые студентами в рамках высшего образования, являются теоретической базой, на которой основывается их подготовка по военным специальностям. При этом учитывается степень сходства каждой образовательной программы высшего образования с программами военных специальностей. Исходя из той или иной степени сходства были разработаны особые подходы к подготовке военных специалистов в университете. При высокой степени сходства основное учебное время отводилось для проведения практических занятий непосредственно на военной технике. При приемлемой степени сходства осуществлялся контроль уровня практической подготов- 
ленности будущих военных специалистов, и на этой основе определялось соотношение между их теоретической и практической подготовкой.

Обогащение военно-профессиональных знаний, навыков и умений будущих военных специалистов, обеспечение развития их компетенций, формирования у них профессионально важных качеств реализовывалось как путем систематического обновления содержания, так и внедрением в образовательный процесс современных технологий обучения.

В ходе освоения обучающимися блока практических дисциплин в Сибирском федеральном университете использовалась технология case-study и такие средства обучения, как ситуационные задания, проектная деятельность.

Данные технологии были выбраны в связи с тем, что осваиваемые военные специальности насыщены ситуациями, которые характеризуются неопределенностью исходных условий и высокой ответственностью. Эти факторы предъявляют высокие требования к тем профессиональным качествам личности студента, которые обеспечивали бы поиск оптимальных вариантов действий.

На практических занятиях, в ходе тактико-строевых занятий с будущими военными специалистами проводились тренировки по выполнению приемов и способов действий при отработке тактических нормативов. Преподаватели создавали всевозможные ситуации, которые требовали от будущих военных специалистов принятия решения с использованием своих теоретических знаний. При этом у них формировалась уверенность в надежности и высоких боевых качествах отечественного вооружения. Решение разнообразных ситуационных задач являлось наиболее действенным методом подготовки военных специалистов. Кроме того, у них повышалась работоспособность, формировались такие важные волевые качества, как терпеливость, внимательность и самоконтроль. Решение ситуационных задач также способствовало функциональному совершенствованию организма будущих военных специалистов и приспособлению их к сложным условиям военной действительности. Кроме того, решение ситуационных задач в составе расчета, экипажа, отделения, взвода способствовали сплочению воинского коллектива, формированию взаимовыручки и взаимопомощи, чувства товарищества.

В процессе подготовки военных специалистов широко использовались тренажеры, которые позволяют проводить тренировки по заранее подготовленным программам, воспроизводящим работу реальной военной техники. В учебном процессе использовались учебные командные пункты радиотехнических войск воздушно-космических сил, которые оснащены средствами отображения, позволяющие в реальном времени обрабатывать радиолокационную информацию.

Компьютерный артиллерийский полигон использовался для решения ситуационных заданий в области применения артиллерийского вооружения, позволяющий выполнять все огневые задачи с закрытых огневых позиций в режиме определенного реального времени. Результаты опытно-экспериментальной работы, проведенной автором в 2014-2019 гг., показал эффективность реализации организационно-педагогических условий адаптации военных специалистов к профессиональной деятельности в Сибирском федеральном университете. Если в начале опытно-экспериментальной работы как у студентов, так и у курсантов преобладал низкий уровень адаптированности к профессиональной деятельности 47,25 и 56,4 \% соответственно, а высокий уровень продемонстрировали $10,5 \%$ студентов и 8,4 \% курсантов, то на завершающем этапе произошли существенные изменения. Количество студентов с низким уровнем адаптированности сократилось до $18,06 \%$, а курсантов до 20 \%. Высокий уровень адаптированности показали 35,08 \% студентов и 34 \% курсантов.

\section{Выводы}

Таким образом, процесс адаптации военных специалистов к профессиональной деятельности в ходе подготовки по военно-учетным специальностям направлен на формирование мотивов прохождения военной службы, профессионально важных ценностей, осво- 
ение знаний, умений, навыков, развитие организационно-волевых качеств, усвоение ценностей, традиций, норм, уставных взаимоотношений в воинских коллективах.

Результаты проведенной опытно-экспериментальной работы подтвердили необходимость и достаточность организационно-педагогических условий, обеспечивающих эффективность адаптации к профессиональной деятельности военных специалистов в ходе их военно-профессиональной подготовки.

\section{Список литературы}

1. Абульханова-Славская К.А. 1980. Деятельность и психология личности. М., Наука, $336 \mathrm{c}$.

2. Адольф В.А., Дашкова Е.К. 2017. Адаптация студентов вуза к будущей профессиональной деятельности. Сибирский педагогический журнал, 1: 61-67.

3. Адольф В.А., Фоминых А.В. 2017. Конкурентоспособность выпускников современного вуза. Красноярск, РИО КГПУ им. В.П. Астафьева, 280 с.

4. Асьянов Х.А. 2000. Организационно-педагогические условия создания и функционирования сельского образовательного комплекса. Автореф. дис. ... канд. пед. наук. Казань, 183 с. $432 \mathrm{c}$.

5. Афанасьев В.Г. 1981. Общество: системность, познание и управление. М., Политиздат,

6. Безюлева Г.В. 2008. Психолого-педагогическое сопровождение профессиональной адаптации учащихся и студентов. М., НОУ ВПО Московский психолого-социальный институт, $320 \mathrm{c}$.

7. Беликов В.А. 2010. Образование, Деятельность, Личность. М., Академия Естествознания, $339 \mathrm{c}$.

8. Выготский Л.С. 2010. Педагогическая психология. М., АСТ, 678 с.

9. Жилин Г.П. 2001. Организационно-педагогические условия управления инновационными процессами в политехническом колледже. Автореф. дис. ...канд. пед. наук. Елец, 22 с.

10. 13верева М.В. 1987. О понятии «дидактические условия». Новые исследования в педагогических науках, 1: 29-32.

11. Игнатова В.В., Девятловский Д.Н., 2014. Методика оценки и контроля сформированности праксиологических умений студентов. AlmaMater. Вестник высшей школы. AlmaMater, 1: 62-65.

12. Ковалев А.Г. 1980. О проблеме восприимчивости личности к воспитательным действиям. Советская педагогика, 6: 38-43.

13. Кочнева Л.П. 2015. Приоритетные тенденции формирования единого образовательного пространства. URL: http://refleader.ru/jgejgepolrnaotr.html (дата обращения: 20.02.2020). ГПИ, $73 \mathrm{c}$

14. Краевский В.В. 1994. Методология педагогического исследования. Самара, Самарский

15. Михайлова Ю.Н. 2010. Развитие адаптационного потенциала личности студента как фактор оптимизации образовательного пространства вуза. Психологические науки и образование, 5: 19-24.

16. Павлов С.Н. 1999. Организационно-педагогические условия формирования общественного мнения органами местного самоуправления. Автореф. дис. ... канд. пед. наук. Магнитогорск, $23 \mathrm{c}$.

17. Платонов К.К. 1986. Структура и развитие личности. М., Наука, 256 с.

18. .Ромм М.В. 2003. Социальная адаптация личности как объект философского анализа. Автореф. дис. ... д-ра философ. наук. Томск, 48 с.

19. Рубинштейн С.Л. 2000. Основы общей психологии. СПб., Питер, 712 с.

\section{References}

1. Abulkhanova-Slavskaya K.A. 1980. Deyatel'nost' i psihologiya lichnosti [Activity and personality psychology]. Moscow, Publ. Nauka, 336 p.

2. Adolf V.A., Dashkova E.K. 2017. Adaptation of University Students for Future Careers, Siberian Pedagogical Journal. 1: 61-67 (in Russian)

3. Adolf V.A., Fominykh A.V. 2017. Konkurentosposobnost' vypusknikov sovremennogo vuza [Competitiveness of graduates of a modern university]. Krasnoyarsk, Publ. RIO KGPU im. V.P. Astaf'yeva, 280 p. 
4. Asyanov H.A. 2000. Organizatsionno-pedagogicheskiye usloviya sozdaniya i funktsionirovaniya sel'skogo obrazovatel'nogo kompleksa [Organizational and pedagogical conditions for the creation and functioning of the rural educational complex]. Abstract. dis. ... cand. ped sciences. Kazan, 183 p.

5. Afanasyev V.G. 1981. Obshchestvo: sistemnost', poznaniye i upravleniye [Society: systemicity, knowledge and management]. Moscow, Publ. Politizdat, $432 \mathrm{p}$.

6. Bezuleva G.V. 2008. Psihologo-pedagogicheskoe soprovozhdenie professional'noj adaptacii uchashchihsya i studentov [Psychological and pedagogical support of professional adaptation of pupils and students]. Moscow, Publ. NOU VPO Moskovskiy psikhologo-sotsial'nyy institut, 320 p.

7. Belikov V.A. 2010. Obrazovaniye, Deyatel'nost', Lichnost' [Education, Activity, Personality]. Moscow, Publ. Akademiya Yestestvoznaniya, 339 p.

8. Vygotsky L.S. 2010. Pedagogicheskaya psikhologiya [Pedagogical psychology]. Moscow, Publ. AST, 678 p.

9. Zhilin G.P. 2001. Organizacionno-pedagogicheskie usloviya upravleniya innovacionnymi processami v politekhnicheskom kolledzhe [Organizational and pedagogical conditions for the management of innovative processes in the Polytechnic College]. Abstract. dis. ... cand. ped sciences. Yelets, $22 \mathrm{p}$.

10. Zvereva M.V. 1987. O ponyatii «didakticheskie usloviya» [On the concept of "didactic conditions"]. Novye issledovaniya v pedagogicheskih naukah, 1: 29-32.

11. Ignatova V.V., Devyatlovskii D.N. 2014. Metodika ocenki i kontrolya sformirovannosti praksiologicheskih umenij studentov [Methodology for assessing and monitoring the formation of praxiological skills of students]. Alma Mater. Vestnik vysshey shkoly. Alma Mater, 1: 62-65.

12. Kovalev A. G. 1980. O probleme vospriimchivosti lichnosti k vospitatel'nym deystviyam [On the problem of the receptivity of personality to educational activities]. Sovetskayapedagogika, 6: 38-43.

13. Kochneva L.P. 2015. Prioritetnye tendencii formirovaniya edinogo obrazovatel'nogo prostranstva [Priority trends in the formation of a single educational space]. Available at: http://refleader.ru/jgejgepolrnaotr.html (accessed: 20 August 2019).

14. Kraevsky V.V. 1994. Metodologiya pedagogicheskogo issledovaniya [Methodology of pedagogical research]. Samara, Publ. Samarskiy gosudarstvennyy pedagogicheskiy institut, $73 \mathrm{p}$.

15. Mikhailova Yu.N. 2010. Development of Adaptation Potential of Student's Personality as a Factor of University's Educational Space Optimization. Psychological science and education, 15 (5): 19 24 (in Russian)

16. Pavlov S.N. 1999. Organizatsionno-pedagogicheskiye usloviya formirovaniya obshchestvennogo mneniya organami mestnogo samoupravleniya [Organizational and pedagogical conditions for the formation of public opinion by local authorities]. Abstract. dis. ... cand. ped. sciences. Magnitogorsk, $23 \mathrm{p}$.

17. Platonov K.K. 1986. Struktura i razvitiye lichnosti [The structure and development of personality]. Moscow, Publ. Nauka, 256 p.

18. Romm M.V. 2003. Sotsial'naya adaptatsiya lichnosti kak ob"yekt filosofskogo analiza [Social adaptation of personality as an object of philosophical analysis]. Abstract. dis. ... Dr. philosopher. sciences. Tomsk, $48 \mathrm{p}$.

19. Rubinstein S.L. 2000. Osnovy obshchey psikhologii [Fundamentals of General Psychology]. St. Petersburg, Publ. Piter, 712 p.

\section{ИНФОРМАЦИЯ ОБ АВТОРЕ}

Корытков Владимир Александрович, кандидат педагогических наук, доцент кафедры педагогики и психологии института истории и гуманитарного образования Новосибирского государственного педагогического университета, г. Новосибирск, Россия

\section{INFORMATION ABOUT THE AUTHOR}

Vladimir A. Korytkov, Candidate of Pedagogical Sciences, Associate Professor, Department of Pedagogy and Psychology, Instituteof History and Humanitarian Education, Novosibirsk State Pedagogical University, Novosibirsk, Russia 